\title{
LA RELEVANCIA SOCIOLÓGICA DE LA ILUSTRACIÓN ESCOCESA
}

\section{THE SOCIOLOGICAL RELEVANCE OF THE SCOTTISH ENLIGHTENMENT}

\author{
ISABEL WeNCES \\ Universidad Carlos III de Madrid. España \\ iwences@polsoc.uc3m.es
}

\begin{abstract}
RESUMEN
La llustración escocesa es uno de los acontecimientos más significativos de la historia cultural del siglo XVIII. Sin embargo, gran parte de sus aportaciones han sido desatendidas por los académicos de lengua española y los que se han acercado a su estudio lo han hecho, en general, desde la filosofía o la economía. Este trabajo intenta atender a la insuficiencia de una aproximación desde la sociología con base en dos objetivos. Por un lado, destacar las aportaciones más significativas de los ilustrados escoceses a la ciencia social y, por el otro, dar a conocer lecturas que teóricos sociales de los siglos XX y XXI han realizado sobre la llustración escocesa.
\end{abstract}

\section{Palabras Clave}

Adam Ferguson, Adam Smith, John Millar, Teoría social de la llustración escocesa.

\section{SUMMARY}

Scottish Enlightenment is one of the most significant intellectual movements of the eighteenth century's cultural history. Nonetheless, Spanish-speaking researchers have neglected a large part of the contributions associated to it, or studied them mainly from an economical or a philosophical standpoint. The present work intends to bridge this gap by approaching this period from a sociological outlook. It is based on two objectives: On one side, to highlight the most significant contributions of Scottish Enlightenment to social science and, on the other side, to acknowledge specific lectures realized by social theoreticians of the twentieth and twentyfirst centuries on the Scottish Enlightenment period.

\section{KEYWORDS}

Adam Ferguson, Adam Smith, John Millar, Social Theory of the Scottish Enlightenment. 


\section{LA RELEVANCIA SOCIOLÓGICA DE LA ILUSTRACIÓN ESCOCESA}

Es generalmente aceptada la afirmación de que el término "sociología" fue acuñado por Augusto Comte en los años treinta del siglo XIX', bautizando con ello a la ciencia que estudiaba al hombre y a los fenómenos sociales. No obstante, también suele haber consenso en considerar que "había sociología antes de que Comte inventara la palabra" (MacRae, 1961:16), porque es difícil negar que reflexiones rigurosas sobre el mundo social cuenten con antecedentes relevantes. Algunos de estos se encuentran en los ilustrados escoceses, quienes cultivaron un semillero de reflexiones que se acercan considerablemente al punto de partida de la moderna sociología, aun cuando no utilizaron el vocabulario ni la metodología que ésta desarrollaría posteriormente.

Introducirse en el mundo de la llustración escocesa resulta sumamente enriquecedor, no sólo desde una perspectiva historiográfica, que en sí misma es legítima, sino porque algunas de sus ingeniosas y originales ideas han influido intensamente en el pensamiento social del siglo XX. Cuando se alude a los orígenes y desarrollo de la sociología es importante distinguir entre aquellos escritores que reflexionaron sobre temas propios de la sociología dentro de discursos no sociológicos, como Aristóteles, Platón, Hobbes - Locke, y aquellos genuinos precursores que estudiaron la realidad social de manera sistemática, analítica y empírica, como es el caso de algunos ilustrados escoceses². Ello explica que entre las diversas lecturas contemporáneas que se hacen sobre la llustración escocesa exista una que dirija su atención a leer a los filósofos morales escoceses con los ojos de la sociología.

El objetivo del presente trabajo es doble. Por un lado, otorgar visibilidad a distintos y representativos enfoques que desde la sociología se han hecho sobre la llustración escocesa. Y, por el otro, exponer algunas de las más significativas aportaciones de los ilustrados escoceses a la ciencia social. Este doble objetivo se lleva a cabo de la mano de tres coordenadas que se titulan: los lectores, los pensadores y los tópicos.

${ }^{1}$ Comte introdujo el vocablo en Curso de Filosofía positiva cuya obra, en seis volúmenes, fue progresivamente viendo la luz entre 1830-1842.

${ }^{2}$ No es objeto de este trabajo discutir cuándo nace la sociología. Sin embargo, de cara a lo que aquí se desarrolla, cobra relevancia la distinción entre la teoría social heredada y la sociología como "práctica intelectual controlada por normas, principios y protocolos semejantes a los de las ciencias socialmente reconocidas como tales, esto es, las de la naturaleza" (Rodríguez Zúñiga, 1991:197). Este mismo autor señala, más adelante, que los moralistas escoceses de la segunda mitad del siglo XVIII son fundamentales y obligan "a plantearse hasta qué punto unas ideas tan distantes de las de Comte pueden ser consideradas también como el origen de la sociología” (Rodríguez Zúñiga, 1991:201). 


\section{LOS LECTORES}

Los estudios en torno a la contribución de los ilustrados escoceses a la sociología y a la antropología social tuvieron una primera aproximación con la obra de Albion Small, Adam Smith and Modern Sociology, publicado en 1907. Pero para conocer investigaciones más profundas y amplias hubo que esperar los trabajos de Werner Sombart, William C. Lehmann y Gladys Bryson, que verían la luz en las décadas veinte y treinta del siglo XX. Después de ellos tendrá lugar un periodo de olvido que sería subsanado en los años sesenta y setenta, donde va a presenciarse un renacimiento de este interés con, por un lado, la aparición de una antología de textos editada e introducida por Louis Schneider y con, por el otro, los estudios de Alan Swingewood, Donald G. MacRae, Ted Benton, Ronald Meek y Edward Evans-Pritchard. Años más tarde aparecerían nuevas reflexiones sobre el tema elaboradas por académicos como Björn Ericsson y Juan Salcedo, entre otros.

Alan Swingewood es uno de los lectores que más seriamente han estudiado los alcances sociológicos de los escritos de los escoceses. Entre sus reflexiones destaca aquella dirigida a señalar que es errónea la interpretación de la sociología que ubica sus orígenes alrededor de las primeras décadas del siglo XIX en torno a Comte, Mill y Le Play. El argumento de este mito es que:

el deseo por obtener una información y un estudio objetivo del cambio social a comienzos del siglo XIX multiplicó los esfuerzos por descubrir métodos estadísticos y matemáticos que pudiesen recoger hasta los datos más precisos. Por ello, florecieron una tecnología y especialización con auténtica apariencia de ciencia [...]. Sin embargo, en la década precedente en Gran Bretaña ya se había dado un intento de interpretar el mundo social. En Escocia, entre 1750 y 1790, las obras de Adam Smith, Adam Ferguson y John Millar constituyen un moderno tratamiento sociológico de la sociedad y del surgimiento de sus instituciones, una tradición que sería ignorada durante el siglo XIX (Swingewood, 1970:136).

En efecto, esta tradición sociológica ha sido durante mucho tiempo subestimada, puesto que ha habido una fuerte tendencia a concentrar las contribuciones de la llustración escocesa en el ámbito de la filosofía y la economía. Swingewood considera que es de suma importancia ubicar a los escoceses como representantes de una escuela de teoría social que, en diversos aspectos esenciales, discrepa con las tendencias sociológicas dominantes tanto en la Inglaterra como en la Europa continental del siglo XIX (Swingewood, 1984:19).

Los escoceses desarrollan "una radical, secular y extraordinaria interpretación científica del mundo social" abarcando temas relacionados con los rangos sociales, el papel social de la propiedad, las formas de gobierno y las secuelas sociales y humanas de la división del trabajo así como el desarrollo del lenguaje. De esta manera, los científicos sociales de la llustración escocesa hablan con "voz moderna" cuando se acercan a problemas tales como el conflicto, la estratificación y las consecuencias sociales de la división del trabajo, temas que "hoy en día conocemos como la esencia de la investigación sociológica" (Swingewood, 1970:136, 147; 1984:19). 
Esta manera de aproximarse a la cuestión se asemeja a la llevada a cabo por Louis Schneider, quien sugiere que es de sumo interés analizar las "observaciones sociológicas, y las concepciones y descripciones que constituyen el argumento central de los trabajos de estos sociólogos" (Schneider, 1967: XV). Ejemplo de ello es el hecho de que sus sistemas de pensamiento son un antecedente del análisis estructuralfuncional (Schneider, 1967:XLVII) ${ }^{3}$.

Schneider y otros autores encuentran en los ilustrados escoceses una gran capacidad para reflexionar sobre temas que hoy en día forman parte de lo que se denomina sociología. Entre éstos destacan el análisis empírico de las relaciones sociales, de las instituciones y de las costumbres arraigadas en la naturaleza humana. Es un tipo de investigación que en su búsqueda por conocer el funcionamiento de la naturaleza humana sustituye el recurso exclusivo a la razón por una base empírica donde cobran especial relevancia sensaciones y sentimientos. El énfasis en la experiencia humana, reflejado muchas veces en estudios morales de interés psicológico, los lleva a indagar y delinear los sentimientos y modos de conducta del hombre. Lo cual significa que estos pensadores protagonizaron un respetable contrapeso al racionalismo.

En realidad, esta perspectiva ya había sido anteriormente planteada por Gladys Bryson, quien se refiere a los ilustrados escoceses como filósofos morales, ya que su investigación tiene como fundamentación última la filosofía moral. Las formas de organización y la conducta social se establecen con base en valores dictados por la ética; ser un filósofo moral no sólo significa tener en cuenta cuestiones éticas, "sino también abarcar el origen de la constitución del hombre, el funcionamiento de sus instituciones, el progreso y las perspectivas de futuro. Por ello, de la esfera de la filosofía moral emergieron varias ramas de lo que más tarde serían las ciencias sociales en el siglo XIX" (Bryson, 1939:405-406).

La apreciación de que "al estudiar a los filósofos morales del siglo XVIII llegamos a los verdaderos precursores de las ciencias sociales" (Bryson, 1939:406) ${ }^{4}$ es compartida por Hayek, quien afirma que "los filósofos morales escoceses del siglo XVIII establecieron los logros de una investigación social que influyó notablemente en la construcción de los esquemas de dos ciencias de reciente creación: la etología y la antropología" (Hayek, 1985:144). De acuerdo con el premio nobel, con los ilustrados escoceses se asistía al nacimiento de nuevos fenómenos que requerían de "todo un nuevo corpus teórico del conocimiento del que, finalmente, surgirían las ciencias sociales" (Hayek, 1988:51).

Una de las notas características de los ilustrados escoceses es su constante esfuerzo por analizar y comprender la evolución de la sociedad así como la propia sociedad en

\footnotetext{
${ }^{3}$ Una impresión similar se desprende de Hermann Strasser, quien cree que algunos de los planteamientos de Ferguson son explícitas anticipaciones del método funcionalista. Su Ensayo sobre la historia de la sociedad civil, sostiene, "representa el más distinguido trabajo que en la sociología temprana utiliza el análisis funcional" (Strasser, 1976: 55).

${ }^{4}$ Sobre este punto, véanse de la misma autora (1932a; 1932b; 1932c).
} 
la que ellos vivían; su objeto de estudio es "el hombre y sus instituciones con un claro esfuerzo por mantener un compromiso con la realidad empírica", y en este sentido, "los científicos sociales del siglo XX pueden considerar a los escoceses pioneros de un esfuerzo en el que ellos mismos están comprometidos: la observación de la sociedad" (Bryson, 1968:11).

Otro lector que pone el acento en la relevancia sociológica de la llustración escocesa es Björn Eriksson quien, a principios de la década de los noventa del siglo recién terminado, planteó que en la llamada "Escuela Histórica Escocesa" se encuentra un discurso sociológico emergente, "un camino o manera sociológica de analizar y discutir la sociedad” (Eriksson, 1993:252).

Dos son las tesis que sugiere este autor y las expresa con un ánimo más expositivo que crítico. En primer lugar, menciona que el "nuevo discurso sobre la sociedad, surgido alrededor de 1750 principalmente en Escocia pero también en Francia, es sociológico" (Eriksson, 1993:253). Con esta afirmación, reconoce que no está aportando nada original, pero, a pesar de ser una idea reiteradamente expuesta, no ha venido a formar parte de la historia de la sociología ni tampoco ha sido defendida con sólidos argumentos. La segunda tesis es, a decir de sus palabras, más original, pero al mismo tiempo menos significativa. De acuerdo con él, este nuevo discurso sobre el análisis de la sociedad es un ejemplo de "rupture épistémologique" . Esto significa, primero, que el nuevo discurso nace como resultado de la llegada de fenómenos complejos, cuya explicación no es posible mediante el conjunto de concepciones hasta entonces utilizadas; segundo, que la resolución de problemas que vienen de la mano de estos fenómenos pasa por el uso de instrumentos teóricos nunca antes utilizados sistemáticamente; y, tercero, que el uso de estos instrumentos significaba la ruptura con otras nociones contemporáneas sobre la sociedad y la historia.

Son prácticamente inexistentes los estudios que en lengua española se han hecho acerca de la relevancia sociológica de la llustración escocesa, por lo que resulta significativo aludir al trabajo de Juan Salcedo. Este autor considera "que el periodo histórico conocido como la Ilustración escocesa (The Scottish Enlightenment) es el momento clave en el que en Europa se inicia de manera irreversible el cambio profundo de un pensamiento de corte teológico-filosófico, al pensamiento sociológico" (Salcedo, 1987:148). Insiste en la necesidad de romper con aquellas visiones que han encasillado la obra de Ferguson presentándola únicamente como filosofía moral y política, o la de Smith relegándole al papel de creador de la economía moderna o de fundador del liberalismo. Ante esta visión reduccionista el autor busca "reivindicar el papel de Ferguson y Smith como sociólogos, en paridad con Montesquieu, y demostrar y realzar su potencial influencia en la sociología del siglo XIX y en la contemporánea" (Salcedo, 1987:149). En su estudio ahonda, como él mismo deja entrever, en los relatos de Gómez Arboleya, quien atribuye a los moralistas escoceses una importancia decisiva en la

\footnotetext{
${ }^{5}$ Eriksson toma la idea de rupture épistémologique de la filosofía de la ciencia de Gaston Bachelard.
} 
historia del pensamiento y de la evolución de Occidente, e incluso llega a mencionar, en clara alusión a Ferguson, que "la sociología está en in nuce en la espléndida obra del escocés" (Gómez Arboleya, 1976:277).

\section{LOS PENSADORES}

Evidentemente, no todos los hombres de letras de la Escocia ilustrada pueden ser leídos con los ojos de la sociología o de la antropología. Los principales precursores son tres profesores universitarios: Adam Smith, Adam Ferguson y John Millar. Si bien, pueden encontrarse aportaciones colaterales en muchos de ellos, como en el jurista Lord Kames 0 en el historiador William Robertson.

El primero de ellos, Adam Smith, fue profesor de la Universidad de Glasgow y probablemente el más conocido de los tres, pero no por su faceta de "sociólogo", sino por sus opiniones en materia económica vertidas en su obra La riqueza de las naciones que, lamentablemente, gran parte de sus lectores han recuperado aislándolas del sistema sociológico general del que constituyen una parte esencial. Es importante seguir insistiendo en que su teoría económica se encuentra estrechamente vinculada a una teoría ético-social (Argemi, 1984). Ahora bien, aun cuando en esta obra se aprecian importantes elementos de ese sistema sociológico, a los efectos que aquí interesan pueden encontrarse también notables aportaciones en su Teoría de los sentimientos morales y en sus Lecciones sobre Jurisprudencia.

Smith fue un filósofo sistemático y si se leen sus escritos con detalle puede apreciarse una propuesta estructurada del hombre, la historia y la sociedad. No en vano "se ha ganado el derecho a ser conocido como uno de los arquitectos de nuestro actual sistema social" (Cropsey, 1987:635). El ilustrado escocés constituye para la historia del pensamiento social uno de los pocos casos instructivos, especialmente por su teoría del hombre socializado (Rodríguez-Zúñiga, 1991: 201-202).

Su idea de la naturaleza humana va a convertirse en la llave que permite comprender las normas sociales y los valores, por un lado, y la manifestación institucional de los intereses individuales, por el otro. En su obra Teoría de los sentimientos morales, Smith subraya que son precisamente esos "sentimientos morales" -pasiones, propensiones, afecciones y sentimientos- los que otorgan esencia a la sociedad porque se encuentra en los fundamentos de la moral socialmente implantada; los sentimientos morales significan la expresión inmediata de la vida social (Strasser, 1976:46). Entre estos sentimientos, el de la simpatía cobra especial relevancia para los objetivos que aquí interesa subrayar. La simpatía, esa inclinación espontánea que todos los hombres tienen por participar de los sentimientos de otros, es el fundamento del origen y de las relaciones sociales y, además, se constituye en la base de la teoría ética de Smith al presentarla como una garantía de los juicios morales aprobatorios y reprobatorios. La simpatía desempeña así un papel central en el campo de la moralidad y en el proceso de socialización humana. 
Adam Smith otorga a la simpatía un sentido singular ya que gracias a ella no sólo se comparten los sentimientos de otros, sino también se es consciente de ello. Esto conduce a que se presente una reflexión por parte del espectador de cuáles serían sus propios sentimientos si se encontrase en la situación del otro, lo cual cobra relevancia porque se acentúa que la simpatía no surge tanto de contemplar una pasión como de la situación que la motiva; para que la simpatía se manifieste en plenitud es necesario conocer la causa que la provoca. Se está ante la distinción entre el objeto de la simpatía -la emoción del otro- y la causa de la simpatía -la situación entera que origina la emocióny esto último significa tomar en cuenta la referencia social del observador.

A través del espectador, y de su simpatía, se configura el procedimiento para medir la moralidad de las acciones humanas, lo que desempeña un papel de suma importancia en el entramado social. La sociedad se convierte en el espejo que nos permite reflejarnos y reflexionar sobre nuestra propia conducta. Dicho de otro modo, la sociedad es la medida de la conveniencia de nuestra conducta; sólo en ella el hombre puede saber qué le provoca satisfacción o desolación y conocer hasta qué grado su actuación merece censura o aprobación. De esta manera, "la consciencia es un producto social, un espejo de los sentimientos sociales" (Raphael, 1975:89).

Toda la explicación anterior cobra relevancia porque permite comprender que "la combinación de imaginación, simpatía y necesidad del amor y de la aprobación constituyen el fundamento del alegato de Smith respecto a que la naturaleza forma a los hombres para la sociedad" (Cropsey, 1975:135). Lo que importa subrayar entonces es que la simpatía tiene importantes implicaciones en el orden social debido a que su presencia interacciona necesariamente con otros afectos, creencias, costumbres y opiniones constituyéndose, de esta manera, en una importante pieza del entramado social. Smith demuestra cómo las costumbres condicionan las actitudes y los comportamientos sociales, transformando valores en hábitos sociales. En suma, conocer la visión de Smith de la naturaleza humana, del hombre socializado, es lo que permite comprender, en general, su teoría global de la sociedad y, en particular, sus reflexiones sobre la estratificación social, sobre la división del trabajo y sobre el cambio social y su relación con la ley de las consecuencias no intencionadas de la acción.

El segundo profesor, esta vez de la Universidad de Edimburgo, es Adam Ferguson, quien recientemente ha conseguido un importante reconocimiento gracias al auge de la literatura en torno a la sociedad civil y la tradición republicana. Sus aportaciones al pensamiento sociológico se encuentran condensadas en su Ensayo sobre la historia de la sociedad civil que en su época le valió fama y reconocimiento.

Algunos lectores han tenido la osadía de afirmar que la sociología empezó con Ferguson, pero sentencias como ésta "carecen ya de trascendencia" (MacRae, 1969:27) y "son hoy tan frecuentes que se han vuelto monótonas" (Bottomore y Nisbet, 1978:45). Lo realmente importante es reconocerlo como una "figura histórica interesante" y fundamental dentro de la sociología, ya que "si se lee con atención, no sólo es instructivo y útil, sino que puede sorprendernos con insospechadas sugerencias, puntos de vista e ideas que merecen atención y estudio" (MacRae, 1969:18 y 25). Por lo tanto, aun 
cuando nos situemos lejos de considerar que es posible otorgar a un único pensador la paternidad de la sociología, no cabe duda de que las páginas de Ferguson dedicadas a "temas sociológicos... son un triunfo no modesto sino de grandes proporciones" (Bottomore y Nisbet, 1978:46).

De lo anterior se desprende que la obra de Adam Ferguson, "una de las principales figuras en la historia del pensamiento sociológico", es "fascinante" porque ilustra muchos "de los supuestos básicos que encontramos en la antropología social moderna" (Evans-Pritchard, 1987:58). Los temas que permiten asociar a este ilustrado escocés con la ciencia social son, en primer lugar, el estudio de las sociedades con base en la observación y la inducción y la defensa de la sociabilidad natural (Hill, 1996). Las reflexiones vertidas sobre estas materias constituyen el eje que llevó a otro estudioso a señalar que Ferguson es el representante más distintivo del desarrollo de la sociología escocesa y del método naturalista (Lehmann, 1930: 233).

El segundo conjunto de tópicos desarrollados por el profesor de la Universidad de Edimburgo son, por un lado, su interés en el análisis del conflicto y de la lucha como fundamentos de la vida social, en los que han puesto especial atención Lehmann, Gumplowicz y recientemente Lisa Hill6. Y, por el otro lado, su inquietud por las consecuencias sociales y políticas de la división del trabajo.

Desde una perspectiva más extensa, Brewer advierte de la importancia que Ferguson concede a la cuestión de la división del trabajo, sobre todo sus consecuencias sociales y políticas. Con base en ello, considera que la construcción intelectual del literato es un puente que va del moralismo del humanismo cívico al tratamiento sociológico de la estructura social. Lo que viene a decir Brewer es que el trabajo de Ferguson muestra una constante tensión, a veces subestimada o ignorada por las interpretaciones sociológicas del siglo XIX, entre el lenguaje del humanismo cívico, centrado en la virtud y la ciudadanía, y el posterior discurso sobre la estructura social, referente a la propiedad privada, la estratificación social, el poder, la explotación industrial y la alienación que produce la división del trabajo. Lo interesante aquí "es que su humanismo cívico toma una dirección sociológica" y esto es lo que le distingue, sintetiza Brewer, de "sus contemporáneos escoceses cuyo humanismo cívico toma la dirección de la economía política clásica" (Brewer, 1987: 24; 1986; 1989).

El tercer ilustrado es John Millar, "uno de los más interesantes y gratificantes autores sociológicos", quien ocupó durante cuarenta años la Cátedra de Derecho de la Universidad de Glasgow y cuya obra Observations Concerning the Origin of the Distinction of Ranks in Society podría muy bien ser "un tratado de sociología moderna" (Evans-Pritchard, 1987:70). Pocos investigadores contemporáneos se han interesado seriamente por Millar y su obra, y es probable que esta "ignorancia de la notable aportación de Millar sea lo que más ha obstaculizado el reconocimiento de la verdadera significación del trabajo de la escuela en su conjunto" (Meek, 1967:59).

\footnotetext{
${ }^{6}$ Véanse especialmente: (Lehmann, 1930) (Gumplowicz, 1892) y (Hill, 2001).
} 
La lectura de Millar como sociólogo se basa principalmente en la tipología que realiza de las sociedades y de su análisis de la estratificación social con base en el rango, donde muestra las causas y las condiciones del prestigio, el poder y el carácter en cada tipo de comunidad socioeconómica. Con Millar asistimos a "una clara y consistente búsqueda con el fin limitado de descubrir el origen y el desarrollo de la estructura de clases. En la época en que fue escrito, esto era un logro extraordinario" (Evans-Pritchard, 1987:74). Asimismo, podría agregarse que Millar se preocupó por los usos, costumbres e instituciones en tanto que determinan las relaciones sociales de los hombres. Asignó un gran peso a la costumbre en la formación de la ley; señaló, al igual que Ferguson, los efectos nocivos de la división del trabajo; y analizó las desigualdades entre los hombres, mismas que atribuía a las diferencias de capacidad y de realización y al anhelo por honrar a los superiores. Sin embargo, Millar no buscaba la desaparición de estas desigualdades porque para él una sociedad sin rangos no existe. Estas preocupaciones han llevado a Robert Maclver a compartir con William Lehmann la idea de que Millar es "un pensador seminal y un precursor de la sociología" (Maclver, 1960:XII). Lehmann, antes de la edición en 1960 de su libro sobre el pensamiento de Millar, escribe un artículo en el cual lo califica de "sociólogo histórico" y donde asienta que su mayor contribución a la teoría sociológica es la de su teoría del dominio de los "factores tecno-económicos" en la dinámica social, el cambio social y las instituciones sociopolíticas (Lehmann, 1952:41). Esta afirmación de Lehmann tiene su antecedente en Werner Sombart, quien considera que la obra de Millar es asombrosa gracias a su formulación de una teoría social tecnoeconómica.

Otras contribuciones, si bien menos sistemáticas, pueden apreciarse en el jurista Henry Home, mejor conocido como Lord Kames o en el historiador y también profesor William Robertson. Lord Kames, escritor prolífico y representante de la primera generación de los ilustrados escoceses, dedicó, al igual que sus contemporáneos, parte de sus esfuerzos analíticos a reconstruir la historia del hombre en su avance desde el salvajismo hasta la civilización y se percató de que a medida que la sociedad evoluciona se originan diversas consecuencias sociales. Su obra Sketches of the History of Man (1774) ejerció una considerable "influencia en el desarrollo del pensamiento antropológico social"; una de sus aportaciones centrales, aun cuando él mismo rompió su propia regla, fue haber dejado "establecida una orientación sólida para que los antropólogos la siguieran: que no se han de sacar conclusiones generales de los hechos particulares"; esta premisa cobra relevancia porque muchos antropólogos de habla inglesa que se encuentran dominados por el trabajo de campo empírico han olvidado este consejo, que es diferente a decir que no se debe tratar lo general en lo particular (Evans-Pritchard, 1987:54).

Si se leen con atención los estudios históricos de William Robertson, profesor y rector de la Universidad de Edimburgo, pueden encontrarse reflexiones puntuales y de sumo interés derivadas de las observaciones empíricas que este ilustrado hizo sobre el curso del desarrollo social. Lo primero que hay que destacar es que fue sumamente riguroso en el uso de las fuentes bibliográficas, lo que le llevó a criticar con dureza a aquellos que creían hacer historia social basándose en crónicas más que en estudios etnográficos. Lo 
segundo que cobra relevancia es que este ejercicio de prudencia lo llevaría a sentar las bases de un método comparado de análisis. Para Robertson, "la comparación imparcial de los hechos" obtenidos gracias a las descripciones elaboradas por los misioneros y los viajeros era de suma importancia para reconstruir acontecimientos pasados y explicar comportamientos presentes (Robertson: 1777) ${ }^{7}$. Este tipo de análisis histórico le convirtió en uno de los primeros pensadores en establecer una relación causal entre relaciones de propiedad y forma de Estado. Compartiría con el resto de los ilustrados escoceses una inquietud por el análisis del desarrollo histórico de la sociedad con base en la teoría de los estadios, poniendo el acento en el modo de subsistencia como criterio central de observación.

\section{Los TÓPICOS}

El tema central de investigación de los ilustrados escoceses es la vida humana. Consideraban que el comportamiento de la naturaleza humana debía ser cuidadosamente observado porque sólo ello les permitiría descubrir los mecanismos de la psicología individual y comprender la vida social. Así, en los filósofos sociales que otorgaron entidad a la llustración escocesa "encontramos una voluntad permanente por comprender al hombre, no por una inquietud metafísica, sino por el deseo de observar de una manera metódica sus manifestaciones sociales y culturales" (Faure, 1986:424-425). Este ejercicio de indagación, que se basó en los lineamientos metodológicos que Isaac Newton había aplicado al estudio de las ciencias naturales y en la epistemología empírica, los llevó a desarrollar una serie de hipótesis o supuestos teóricos sobre el proceder humano y los fenómenos sociales. Así, el interés de los ilustrados escoceses por la naturaleza del ser humano se encuentra estrechamente ligada a la necesidad de comprender y analizar empíricamente las distintas formas en que dicha naturaleza se manifiesta en la historia, en la sociedad y en la cultura. En este objetivo, el rechazo a los principios cartesianos de la razón va a ser compartido por todos los filósofos morales escoceses para quienes las sensaciones y los sentimientos se constituirían en fundamentos empíricos.

Dentro del gran conjunto de temas que abarca el pensamiento social, los ilustrados escoceses se concentraron, en primer lugar, en intentar aplicar al análisis histórico y social el modelo teórico desarrollado exitosamente por Newton para explicar el mundo natural. De este modo, los "Newtons of the mind" (Gay, 1969:174), que intentaban dotar de validez científica a sus investigaciones (Skinner, 1967), observaban y analizaban las acciones y reacciones de los hombres y cómo éstas influían en la sociedad, tal si fueran fuerzas centrífugas y centrípetas (Eriksson, 1993: 258).

\footnotetext{
${ }^{7}$ Esta preocupación puede constatarse en fragmentos de su obra The History of America reproducidos y traducidos en (Wences, 2007:112-116).
} 
Con base en la observación, la experiencia y la inducción los pensadores escoceses explicaron la evolución social de la humanidad, la sociedad en la que vivían y rechazaron las especulaciones metafísicas; su conciencia de que la sociedad es un proceso, resultado de fuerzas económicas, sociales e históricas que ellos intentaban identificar a través de una metodología empírica, los coloca en las raíces de la sociología temprana y de la moderna antropología social.

Los estudios históricos sociales de los ilustrados escoceses constituyen un segundo ámbito en el que hicieron contribuciones notables. Estos estudios son considerados como profundamente valiosos porque sentaron las bases de las primeras teorías estructuras del desarrollo sociocultural. De un lado, el auge del método científico desarrollado por Newton y el deseo por aplicar sus premisas al análisis del mundo social y, del otro, su deseo por estudiar la sociedad y la historia natural de la humanidad darían lugar a nuevas teorías sobre la sociedad y sus orígenes en direcciones opuestas a la teoría del contrato social, así como a una curiosidad científica por las costumbres y constituciones de otros pueblos, a estudios de política comparada y al desarrollo de la teoría antropológica.

Las fuentes con base en las cuales los ilustrados escoceses recogieron datos fueron de tres tipos: el mundo contemporáneo "civilizado" de Escocia y Europa, que ellos veían directamente; el mundo contemporáneo "salvaje" de América, Asia y Polinesia, narrado por los viajeros; $y$ el mundo descrito por los pensadores antiguos. Mientras que la primera fuente se basaba en la experiencia personal, las dos restantes requerían necesariamente de observaciones indirectas o secundarias. Así, para evitar el uso indiscriminado de datos, testimonios e indicios, intentaron ser prudentes y cautelosos con la información. Esta actitud se explica gracias a sus aspiraciones "científicas" de carácter social que los hizo actores centrales de la "revolución historiográfica" de principios del siglo XVIII.

Para no quedar a merced de la propaganda o la tergiversación, los historiadores sociales de la llustración escocesa emplearon dos métodos científicos de análisis. De ellos dan cuenta las siguientes palabras de Millar:

Nuestra información acerca de la situación de la humanidad (...) proviene principalmente de relatos [cuya] cantidad y variedad (...) es tal que alcanzan en conjunto un grado de precisión bastante elevado, lo que les hace casi totalmente fiables, y ante los cuales ningún narrador, por muy ilustrado y respetado que sea, puede oponer objeción alguna. Estos diferentes relatos ofrecen al lector la oportunidad de comparar (...) para que a partir de la observación de sus puntos en común y de sus diferencias puedan otorgarles el crédito que crean conveniente (Millar, 1771: 13) ${ }^{8}$.

Esta particular forma de búsqueda y obtención de la información, por una parte, da forma a las primeras aproximaciones de corte estadístico; y, por la otra, da cuenta de que los escoceses practicaron con solidez los esbozos de lo que hoy se denomina método comparado, que en sí mismo conllevaba la idea del cambio social (Berry, 1997:62).

\footnotetext{
${ }^{8}$ Se encuentra traducido en (Wences, 2007: 206).
} 
El deseo de los ilustrados escoceses por comprender las bases de la dinámica y el cambio social constituían a su vez un interés por mostrar los complejos mecanismos económicos, sociales y políticos que han hecho y hacen funcionar a las sociedades. Por ello, para explicar heurísticamente el desarrollo sociocultural y político, los ilustrados escoceses eligieron como instrumento analítico grandes etapas "típico-ideales". Este instrumento, que se daría posteriormente a conocer como la teoría de los estadios del desarrollo social, sería inicialmente anunciado por John Dalrymple y Lord Kames, aplicado por Adam Ferguson y John Millar y teorizado por Adam Smith (Bryson, 1968: cap. III). Esta forma de aproximación al estudio del desarrollo sociocultural dominó una parte considerable del pensamiento socioeconómico europeo de la segunda mitad del siglo XVIII y llegaría a tener un "significado crucial en el desarrollo posterior de la economía, la sociología, la antropología y la historiografía" (Meek, 1981:2).

Cada una de las etapas del desarrollo sociocultural, denominadas caza, pastoreo, agricultura y sociedad civil — civilizada y comercial- (Smith y Millar) o salvajismo, barbarie y sociedad civil (Ferguson), representa un avance con relación al periodo anterior y cada una de ellas se caracteriza por distintas ideas e instituciones relativas al desarrollo cognitivo, la propiedad, el gobierno y el derecho, y percepciones singulares sobre las costumbres, el modo de subsistencia, la moralidad, la división del trabajo, los rangos, el conflicto, etcétera.

Al dirigir su atención a intentar dilucidar las causas que llevaron a la transición de un tipo de sociedad a otra, los ilustrados escoceses analizaron las instituciones dominantes y los principales mecanismos del cambio social. En este ejercicio, una de las instituciones que ocupó gran parte de su interés fue la de la estratificación social. Para Adam Smith el desarrollo de la sociedad comercial dio lugar a una estructura social dividida claramente en tres clases, propietarios, capitalistas y trabajadores, "Ios tres órdenes constituyentes de cada sociedad civilizada". Aun cuando Smith no empleó el concepto de clases sociales -ni tampoco Ferguson ni Millar-, en su trabajo hay claras muestras de esta división. Sin embargo, donde se anuncia con más claridad la articulación de una teoría de clases como categoría sociológica es en los trabajos de Millar. Será este ilustrado escocés quien argumentará con más detalle que el desarrollo social necesariamente da lugar a una desigualdad social que se refleja continuamente mediante la graduación y subordinación de los rangos (Millar, 1771). En su análisis la propiedad, fuente natural de influencia y autoridad, constituye la base de la diferenciación social, la cual se encuentra en cada rincón de la sociedad y directamente relacionada con el cambio social.

Siguiendo la argumentación de Millar, en las sociedades no comerciales y no civilizadas la diferenciación social se basa en gran medida en la ocupación: en las comunidades de pescadores y cazadores los logros personales relevantes, basados en la intrepidez, las habilidades militares y la resistencia, constituyen la base de la autoridad. Pero las distinciones, al depender de la ocupación, son inestables y no pueden dar lugar al establecimiento de autoridades duraderas y con influencia permanente. Sin embargo, subraya Millar, con el desarrollo de la agricultura la adquisición de la propiedad aumenta y los hombres comienzan a distinguirse por sus bienes. El incremento y acumulación 
de la propiedad en tan sólo algunas manos conduce a una permanente diferenciación de rangos y al establecimiento e institucionalización de una autoridad que garantice el derecho a la propiedad.

Es importante subrayar que la herramienta de los estadios del desarrollo social actúa de manera heurística y se utiliza para identificar coherencias en la configuración de las instituciones sociales. Tener claridad en este aspecto cobra relevancia para evitar caer en la extendida creencia de que es un instrumento utilizado para justificar que el modo de subsistencia configura a las instituciones sociales (Haakonsen, 1996). Los ilustrados escoceses subrayaron que la manera en que se encuentra organizada la propiedad influye en el entramado social y político y, por consiguiente, mediante el mecanismo de los estadios del desarrollo social se puede constatar el papel central que ésta desempeña. Es decir, la forma de organización de la propiedad es inseparable de la forma en que el Derecho y el poder funcionan, tanto formalmente -el gobierno- como informalmente -las costumbres-. Sin embargo, la propiedad, si bien fundamental, tan sólo es una institución social más y debe considerarse junto con la ley, los rangos, las costumbres y el gobierno.

Lo que realizaron los escoceses, y que los hace particulares, no es solamente haber analizado la sociedad de manera autónoma, pero entrelazada con el mundo cultural, político y económico, sino también haber considerado los cambios de una forma global. Muchas de las aportaciones sobre la configuración sociocultural, política e institucional ofrecidas por los ilustrados escoceses pueden considerarse como pilares de una posterior ciencia de los cambios culturales e históricos de la sociedad, como son las relaciones entre la acción humana y la estructura social o las consecuencias sociopolíticas de la evolución histórica. Con estas aportaciones nacían las primeras propuestas sistemáticas de la idea de sociedad como un sistema organizado y desarrollado mediante leyes y estadios. Esta reconstrucción, explicada con base en la llamada historia natural de la sociedad fue, sin duda, uno de los mayores logros de la llustración escocesa y permite "apreciar el primer brote de la teoría social moderna" (Callinicos, 1999:24), a la que deben mucho los padres fundadores de la sociología del siglo XIX.

El tercer conjunto de tópicos que engloba las aportaciones de los ilustrados escoceses se centra en su idea de que el orden social es el resultado de actos y procesos cuyas consecuencias, desconocidas previamente, ejercen un significativo impacto en la dinámica social y en la configuración institucional. Insistieron en que los órdenes sociales complejos, el lenguaje, la propiedad, el comercio, la legalidad, los rangos y el gobierno, son el resultado de consecuencias no previstas de acciones individuales. Para ellos, la configuración social y la formación institucional se explican a partir de causas naturales y culturales, alejándose así de la idea de que el hombre es capaz de diseñar racionalmente el complejo sistema de normas, jurídicas y morales, que rigen al mundo. Para los ilustrados escoceses, los hombres pueden elegir racionalmente sus objetivos, pero en general no son conscientes de que los resultados alcanzados pueden ir en sentido contrario o más allá de sus intenciones originales, ni tampoco de que si alguno de sus deseos particulares llega a ser satisfecho se está abriendo a su vez el camino 
para la realización de nuevas aspiraciones. Hay, como bien lo afirma Smith en su Teoría de los sentimientos morales, una especie de contrariedad en este proceso:

\begin{abstract}
Y está bien que la naturaleza nos engañe de esa manera. Esta superchería es lo que despierta y mantiene en continuo movimiento la laboriosidad de los humanos. Fue eso lo que les impulsó primero a cultivar la tierra, a construir casas, a fundar ciudades y comunidades, a inventar y mejorar todas las ciencias y las artes que ennoblecen y embellecen la vida humana; lo que ha cambiado por completo la faz de la tierra, que ha transformado las rudas selvas de la naturaleza en llanuras agradables y fértiles, y ha hecho del océano intransitado y estéril un nuevo fondo para la subsistencia y una gran carrera que comunica las diversas naciones del globo (Smith, 1997:32).
\end{abstract}

Dichos resultados se encuentran atados por las actividades de los hombres dentro del conjunto de la sociedad; resultados ante los cuales el individuo es ampliamente inconsciente y cuya imaginación no podía prever, pero que termina por reconocer. Los hombres son conducidos, de acuerdo con el lenguaje de Smith, a fomentar un fin que no forma parte de su intención original.

La visualización del orden social como resultado de un largo proceso de aprendizaje y de una evolución natural -accidental o espontánea- de la especie, junto con la interpretación de que la configuración institucional, si bien fruto de una actividad plural, no era consecuencia de ciertas directrices o planes inteligentes previos, llevó a los ilustrados escoceses a alejarse de toda explicación ficticia de acuerdo con la cual las instituciones y el orden social son el resultado de las decisiones de un "sabio Legislador" y de aquellas construcciones racionales que sostienen que la sociedad civil es fruto de previa convención. Para autores como Hamowy es en estas consideraciones que se encuentra la aportación sociológica más significativa de los pensadores de la llustración escocesa (Hamowy, 1987:3; 1986:76). Sin duda, la propuesta de que todo hecho social debe comprenderse dentro de su contexto físico, moral y cultural y de que las instituciones sociales altamente complejas no eran necesariamente el resultado de un designio intencional son ideas centrales que dieron origen y nutrieron a las ciencias sociales.

Suele ser frecuente señalar a los procesos económicos como ejemplo más manifiesto de un fenómeno social altamente complejo y no diseñado ni dirigido. No obstante, los ilustrados escoceses no limitaron el uso de la ley de las consecuencias no intencionadas de la acción a explicar fenómenos económicos, sino que se valieron de ella para analizar estructuras sociales y políticas, observar las instituciones encargadas de hacer posible el proceso legal, conocer el sistema de pautas morales y la naturaleza y juego de reglas compartidas bajo las cuales interactúan los hombres, así como para comprender el desarrollo del lenguaje (Wences, 2007:43).

Para ilustrados como Ferguson, las interpretaciones que recurren a un Gran Hombre, o a un Sabio Legislador, no ofrecen una adecuada explicación sobre la configuración de las instituciones sociales; el escocés considera que el supuesto vínculo entre intención e institución es endeble. No niega que los hombres tengan intenciones, incluso admite que pueda existir un grado significativo de la acción deliberada en la vida política. Sin embargo, la acción individual intencionada no es una explicación sólida cuando se trata de 
instituciones. Probablemente, Ferguson sea el ilustrado escocés que más puntualmente subrayó esta situación; hay quienes incluso afirman que "sin duda la formulación más avanzada de la ley de las consecuencias involuntarias de todo el medio siglo XVIII" (Meek, 1981:147) se encuentra en el Ensayo sobre la historia de la sociedad civil. En esta obra, el ilustrado sostiene que las instituciones sociales y políticas aun cuando son "el resultado de actos humanos", no lo son "de la ejecución de un designio humano" (Ferguson, 1966:122), dejando así claramente asentada la idea de que la configuración institucional es consecuencia de la acción involuntaria de los hombres, y no el resultado de algún cálculo racional o de la decisión de un poder omnisciente.

Estas ideas fueron también adoptadas por otros filósofos escoceses cuyo realismo tuvo como triunfo característico la demolición de ciertos relatos como el del Legislador omnisciente (Winch, 1979). En efecto, la destrucción del mito del Sabio Legislador probablemente fue "el efecto más original y atrevido producido en el ámbito de la ciencia social por la llustración escocesa" (Forbes, 1966: XXIV).

Relacionado directamente con el tema de las consecuencias no intencionadas de la acción se encuentra el acento en la función social del conflicto. Adam Ferguson es el ilustrado escocés que más se ocupó de los alcances de la hostilidad natural en la configuración social; a lo largo de su Ensayo sobre la historia de la sociedad civil se constata la importancia del conflicto para la supervivencia institucional y el mantenimiento de la cohesión social (Wences, 2006:154). Al destacar los beneficios que el conflicto genera para el desarrollo social y la preservación de la sociedad civil, Ferguson no sólo se aleja "de las posiciones habituales del siglo en el que vivió" (Bryson, 1968:49-50), sino que además se convierte en "el primer pensador en subrayar de manera categórica los efectos positivos del conflicto" (Hill, 1996:215). Ferguson se aleja del discurso habitual de la época que ponía el acento en la necesidad de abandonar condiciones de violencia para legitimar estados de tranquilidad social (Hobbes); para él, el conflicto no constituye la causa del desorden social, más bien, el orden social nace del propio conflicto y de la confrontación. Este razonamiento cobra relevancia porque se aleja de la órbita de las preocupaciones propias de la jurisprudencia natural y se constituye como una nota característica del discurso sociológico (Ferrarroti, 1984; Hill, 2001)9.

Finalmente, también tiene un tono sociológico la particular lectura que Millar y Ferguson hacen de la división del trabajo. Para ellos, uno de los efectos no intencionados del desarrollo social, consecuencia de una sociedad comercial, es que los hombres van cada día asemejándose más a una máquina, desmantelando poco a poco sus poderes mentales y convirtiéndose en meros instrumentos de trabajo.

Tanto Millar como Ferguson eran conscientes de la estratificación social que generaba la división del trabajo y sus análisis representan una ruptura respecto de la discusión

\footnotetext{
${ }^{9}$ Sombart sostiene que los ilustrados escoceses que se presentan como los adversarios del Derecho natural racionalista -especialmente de la teoría contractual- son los fundadores de la moderna sociología occidental (Sombart, 1962:30).
} 
teórica previa. A pesar de que Montesquieu y Hume subrayaron el significado económico de la división del trabajo, minimizaron los efectos sociales y no se ocuparon del alcance estructural que este fenómeno conlleva. Ferguson, en cambio, subraya que la división del trabajo es tanto una institución social como económica que separa las funciones que demandan habilidades de aquellos trabajos que no requieren ningún ejercicio mental ni ninguna capacidad creativa. El trabajo, entonces, deviene más eficiente cuando se suprimen los sentimientos y los razonamientos y cuando "la ignorancia se convierte en la madre tanto de la industria como de la superstición". En un famoso pasaje, Ferguson apunta que la perfección de la manufactura consiste en "suprimir el uso de la mente para que, sin ningún esfuerzo de imaginación, el taller pueda considerarse como una máquina cuyas piezas son hombres" (Ferguson, 1966: cuarta parte, sección I).

Este ilustrado escocés se da cuenta de los desastrosos efectos que la división del trabajo puede causar al carácter humano y denuncia que el establecimiento del "hombre máquina" puede derivar en dos graves consecuencias. Por un lado, en elevados costos para la cohesión de la vida social; $y$, por el otro, en el riesgo de corromper el espíritu público. De esta manera, la división del trabajo, aun ahí donde podría justificarse debido a las exigencias del progreso, produce incomunicación e indiferencia; cuando esto ocurre el hombre se paraliza y ve mermada su condición activa. Una vez aquí, se está muy próximo al momento en el cual el individuo pierde la conciencia de pertenecer al todo y el sentido del bien público.

Cuando Ferguson subraya las peligrosas consecuencias a las que puede conducir la excesiva especialización utiliza, como variables explicativas, elementos de la estructura social, mostrando una ingeniosa "astucia sociológica" (Brewer, 1989:19) ${ }^{10}$. De esta manera, las críticas de Ferguson sobre las devastadoras repercusiones de la división del trabajo son el preludio de las denuncias que sociólogos de los siglos posteriores realizarán sobre las implicaciones sociales y humanas que este proceso produce en las sociedades industriales. Probablemente, uno de los aspectos más frecuentemente citado de lo que podrían ser las herencias sociológicas de Ferguson es la idea de que en su pensamiento se encuentran indicios de lo que posteriormente Marx daría a conocer como la alienación. Como se sabe, Marx se preocupó profundamente por el problema de la alienación del hombre en la cultura y en el trabajo y en su análisis buscó planteamientos precedentes en el pensamiento político. Encontró indicios en el desarrollo que Ferguson haría sobre los efectos de la división del trabajo, como queda constancia en la referencia que le hace en El Capital (Marx, 1972:373)11.

Sin duda, las páginas de Ferguson sobre la división del trabajo son un modesto triunfo de la sociología del siglo XVIII y ellas sentaron las bases de un "camino que

\footnotetext{
${ }^{10}$ En esta misma dirección véanse (Benton, 1990:111-114), (Macrae, 1969), (Swingewood, 1970).

${ }^{11}$ Similar apreciación puede encontrarse en los trabajos de (Pascal, 1938) y (Meek, 1967) si bien su lectura de los ilustrados escoceses va de la mano de la teoría materialista de la historia. Véase en este mismo sentido a (Skinner, 1965; 1982).
} 
definitivamente anticipa e influye en Saint Simon, Comte, Spencer y Durkheim" (Lehmann, 1930:187) ${ }^{12}$.

Para concluir quisiera mencionar que antes del siglo XIX difícilmente puede encontrarse una separación, tal y como hoy la conocemos, entre la sociología, la economía, la filosofía, la historia y la política. Sin embargo, la forma en que los ilustrados escoceses se aproximaron al estudio de la sociedad, la metodología empírica que emplearon y sus análisis de aspectos económicos, políticos e históricos pueden considerarse significativas aportaciones a la sociología.

\section{Referencias BiBLIOGRÁfICAS}

Argemi, L. 1984. "Adam Smith y la teoría de los sentimientos morales". Sociología contemporánea. Ocho temas a debate. pp. 67-85. Madrid: CIS/Siglo XXI.

Benton, T. 1990. "Adam Ferguson and the Enterprise Culture". En The Enlightenment and its Shadows, P. Hulme y L. Jordanova, eds., pp. 101-120. Londres y Nueva York: Routledge.

Berry, C. 1997. Social Theory of the Scottish Enlightenment. Edinburgh: Edinburgh University Press.

Bottomore, T. y R. Nisbet. 1978. Historia del análisis sociológico. Buenos Aires: Amorrortu Editores.

Brewer, J. 1987. "The Scottish Enlightenment". En Modern Theories of Exploitation. A. Reeve, ed., pp. 6-29. Londres: Sage.

Brewer, J. 1986. "Adam Ferguson and the Theme of Exploitation". The British Journal of Sociology. 38: 461-478.

Brewer, J. 1989. "Conjectural History, Sociology and Social Change in Eighteenth-Century Scotland: Adam Ferguson and the Division of Labour". En The Making of Scotland: Nation, Culture and Social Change. D. McCrone, S. Kendrick y P. Straw, eds., pp. 13-30. Edinburgh: Edinburgh University Press \& The British Sociological Association.

Bryson, G. 1932a. "Sociology Considered as Moral Philosophy". Sociological Review. 24: 22-36.

Bryson, G. 1932b. "The Emergence of the Social Sciences from Moral Philosophy". International Journal of Ethics. XLII: 304-323

Bryson, G. 1932c. "The Comparable Interests of the Old Moral Philosophy and the Modern Social Sciences". Social Forces. XI: 19-27.

Bryson, G. 1939. "Some Eighteenth-Century Conceptions of Society”. Sociological Review. 31: 401-421.

\footnotetext{
12 También Gautier comparte la percepción de que el "modelo de Durkheim de la división del trabajo social se encuentra totalmente contenido en las dos últimas partes del Ensayo" (Gautier, 1992: 86).
} 
Bryson, G. 1968. Man and Society: The Scottish Inquiry of the Eighteenth Century. New York: Augustus M. Kelley.

Callinicos, A. 1999. Social Theory. A Historical Introduction. Cambridge: Polity Press.

Comte, A. 1830-1842. Cours de philosophie positive. París: Bachelier.

Cropsey, J. 1975. "Adam Smith and Political Philosophy". En Essays on Adam Smith. A. Skinner y T. Wilson, eds., pp. 132-153. Oxford: Clarendon Press.

Cropsey, J. 1987. "Adam Smith". En L. Strauss y J. Cropsey, eds., pp.549-572. History of Political Philosophy, Chicago: University of Chicago Press.

Eriksson, B. 1993. "The First Formulation of Sociology. A Discursive Innovation of the $18^{\text {th }}$ Century". Archives Européennes de Sociologie. 34: 251-276.

Evans-Pritchard, E. 1987. Historia del pensamiento antropológico. Madrid: Cátedra.

Faure, M. 1986. "Le "Scottish Enlightenment": Naissance d'une Anthropologie Sociale". Revue de Synthèse. 4: 424-425.

Ferguson, A. 1966. An Essay on the History of Civil Society. Edinburgh: Edinburgh University Press [Primera edición: 1767. Londres: A. Millar \& T. Cadell].

Ferrarotti, F. 1984. "Civil Society and State Structure in Creative Tension: Ferguson, Hegel, Gramsci". State, Culture and Society. 1: 3-25.

Forbes, D. 1966. "Introducción" a An Essay on the History of Civil Society de Adam Ferguson. Edinburgh: Edinburgh University Press.

Gautier, C. 1992. "Introducción" a Essai sur l'histoire de la société civile de A. Ferguson. Paris: Presses Universitaires de France.

Gay, P. 1969. The Enlightenment. An Interpretation, tomo II: The Science of Freedom. Nueva York \& Londres: W.W. Norton and Company.

Gómez Arboleya, E. 1976. Historia de la estructura y del pensamiento social. Madrid: Instituto de Estudios Políticos.

Gumplowicz, L. 1892. Die Sociologische Staatsidee. Innsbruck: Graz.

Haakonssen, K. 1996. Natural Law and Moral Philosophy. From Grotius to the Scottish Enlightenment. Cambridge: Cambridge University Press.

Hamowy, R. 1986. "Progress and Commerce in Anglo-American Thought: The Social Philosophy of Adam Ferguson". Interpretation. 14: 61-87.

Hamowy, R. 1987. The Scottish Enlightenment and the Theory of Spontaneous Order. Carbondale: Southern Illinois University Press. 
Hayek, F. 1985. Derecho, legislación y libertad. Madrid: Unión Editorial.

Hill, L. 1996. "Anticipations of Nineteenth and Twentieth Century Social Thought in the Work of Adam Ferguson". Archives Européennes de Sociologie. 37: 203-228.

Hill, L. 2001. "Eighteenth-Century Anticipations of the Sociology of Conflict: The Case of Adam Ferguson". Journal of the History of Ideas. 62: 281-299.

Lehmann, W.C. 1930. Adam Ferguson and the Beginnings of Modern Sociology. Nueva York: Columbia University Press.

Lehmann, W.C. 1952. "John Millar, Historical Sociologist: Some Remarkable Anticipations of Modern Sociology". British Journal of Sociology. 2: 30-46.

Maclver, R. 1960. "Prólogo". En His Life and Thought and his Contributions to Sociological Analysis, W.C. Lehman. pp. XI-XIII. Londres y Nueva York: Cambridge University Press.

MacRae, D. 1961. Ideology and Society. Londres: Heinemann.

MacRae, D. 1969. "Adam Ferguson". En Los padres fundadores de la ciencia social, T. Raison. ed., pp. 17-27. Barcelona: Anagrama.

Marx, C. 1972. El Capital. Crítica de la economía política. Madrid: EDAF-Ediciones.

Meek, R.L. 1967. "La aportación escocesa a la sociología marxista". Economía e ideología y otros ensayos del mismo autor. Barcelona: Ariel.

Millar, J. 1771. The Origin of the Distinction of Ranks. Londres: John Murray.

Pascal, R. 1938. "Property and Society, The Scottish Historical School of the $18^{\text {th }}$ Century". The Modern Quarterly. 2: 167-179.

Raphael, D.D. 1975. "The Impartial Spectator". En Essays on Adam Smith, A. Skinner y T. Wilson, eds., pp. 114-131. Oxford: Clarendon.

Robertson, W. 1777. The History of America, vol. II. Edinburgh: J. Balfour.

Rodríguez-Zúñiga, L. 1991. "El problema de los orígenes". Revista Española de Investigaciones Sociológicas. 54: 195-211.

Salcedo, J. 1987. "La conciencia sociológica en la llustración Escocesa". Anales de Estudios Económicos y Empresariales. 2: 147-167.

Schneider, L. 1967. "Introducción". The Scottish Moralists on Human Nature and Society. En L. Schneider, ed., Chicago: University of Chicago Press.

Skinner, A. 1965. "Economics and History. The Scottish Enlightenment". Scottish Journal of Political Economy. 12: 1-22. 
Skinner, A. 1967. "Natural History in the Age of Adam Smith". Political Studies. XV: 32-48.

Skinner, A. 1982. "A Scottish Contribution to Marxist Sociology". En Classical and Marxian Political Economy: Essays in Honour of Ronald L. Meek, I. Bradley y M. Howard, eds., pp. 79-114. Londres: The Macmillan Press.

Smith, A. 1997. Teoría de los sentimientos morales. Madrid: Alianza Editorial [Primera edición: 1759].

Sombart, W. 1962. Noo Sociología. Madrid: Instituto de Estudios Políticos.

Strasser, H. 1976. The Normative Structure of Sociology. Londres: Routledge \& Kegan Paul.

Swingewood, A. 1970. "Origins of Sociology: the Case of the Scottish Enlightenment". En The Classical Tradition in Sociology: the European Tradition, R. Boudon, M. Cherkaoui y J. Alexander, eds., pp. 135-151. Londres: Sage.

Swingewood, A. 1984. A Short History of Sociological Thought. Londres: Macmillan.

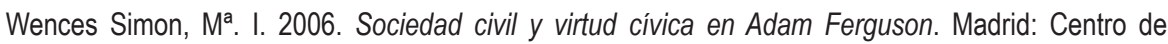
Estudios Políticos y Constitucionales.

Wences Simon, Mª. I. 2007. "Teoría social y política de la llustración escocesa. Una antología”. Madrid: Plaza y Valdés y CSIC.

Winch, D. 1979. Adam Smith's Politics. An Essay in Historiographic Revision. Cambridge: Cambridge University Press.

ISABEL WENCES es Profesora Titular Interina de Ciencia Política de la Universidad Carlos III de Madrid. Licenciada y Máster en Ciencia Política y Doctora en Derecho. Su tesis doctoral sobre el pensamiento ilustrado escocés ganó los premios "Nicolás Pérez Serrano" del CEPC, el de la Asociación Española de Ciencia Política y el extraordinario de doctorado. Entre otros, ha publicado un libro sobre el pensamiento de Adam Ferguson (Madrid: CEPC, 2006), editado una antología de textos sobre la teoría social y política de la llustración escocesa (Madrid: CSIC y Plaza y Valdés, 2007) y acaba de publicar Hombre y sociedad en la llustración escocesa (México: Fontamara, 2009).

RECIBIDO: $14 / 04 / 08$

ACEPTADO: $26 / 11 / 08$

Publicado on-line: 30 de noviembre de 2009 